\title{
Does home blood pressure monitoring improve patient outcomes? A systematic review comparing home and ambulatory blood pressure monitoring on blood pressure control and patient outcomes
}

\author{
This article was published in the following Dove Press journal: \\ Integrated Blood Pressure Control \\ 3 July 2015 \\ Number of times this article has been viewed
}

\author{
Tonya L Breaux- \\ Shropshire ${ }^{1,2}$ \\ Eric Judd' \\ Lee A Vucovich ${ }^{3}$ \\ Toneyell S Shropshire ${ }^{4}$ \\ Sonal Singh ${ }^{5}$ \\ 'Vascular Biology and Hypertension \\ Program, Cardiovascular Disease, \\ School of Medicine, University of \\ Alabama at Birmingham, Birmingham, \\ $\mathrm{AL}, \mathrm{USA} ;{ }^{2}$ Veterans Administration, \\ Birmingham, AL, USA; ${ }^{3}$ Lister Hill \\ Library, University of Alabama at \\ Birmingham, Birmingham, AL, USA; \\ ${ }^{4}$ Department of Physical Therapy, \\ Louisiana State University Health \\ Sciences Center, New Orleans, LA, \\ USA; ${ }^{5}$ Department of Medicine, \\ John Hopkins School of Medicine, \\ Baltimore, MD, USA
}

Objective: Our objective was to compare the clinical effectiveness of home blood pressure monitoring (HBPM) and 24-hour ambulatory blood pressure monitoring (ABPM) on blood pressure (BP) control and patient outcomes.

Design: A systematic review was conducted. We also appraised the methodological quality of studies.

Data sources: PubMed, Scopus, CINAHL, and the Cochrane Central Register of Control Trials (CENTRAL).

Inclusion criteria: Randomized control trials, prospective and retrospective cohort studies, observational studies, and case-control studies published in English from any year to present that describe HBPM and 24-hour ABPM and report on systolic and/or diastolic BP and/or heart attack, stroke, kidney failure and/or all-cause mortality for adult patients. Due to the nature of the question, studies with only untreated patients were not considered.

Results: Of 1,742 titles and abstractions independently reviewed by two reviewers, 137 studies met predetermined criteria for evaluation. Nineteen studies were identified as relevant and included in the paper. The common themes were that HBPM and ABPM correlated with cardiovascular events and mortality, and targeting HBPM or ABPM resulted in similar outcomes. Associations between BP measurement type and mortality differed by study population. Both the low sensitivity of office blood pressure monitoring (OBPM) to detect optimal BP control by ABPM and the added association of HBPM with cardiovascular mortality supported the routine use of HBPM in clinical practice. There was insufficient data to determine the benefit of using HBPM as a measurement standard for BP control.

Conclusion: HBPM encourages patient-centered care and improves BP control and patient outcomes. Given the limited number of studies with both HBPM and ABPM, these measurement types should be incorporated into the design of randomized clinical trials within hypertensive populations.

Keywords: ABPM, HBPM, OBPM, randomized control trials

\section{Introduction}

Based on scientific evidence, national and international guidelines recommend optimizing medication dosages or adding additional antihypertensive medication until target goal blood pressure (BP) is obtained. ${ }^{1,2}$ Obtaining a target goal BP is crucial to prevent poor outcomes such as cardiovascular disease, kidney failure, and stroke. However, approximately $53.5 \%$ of Americans are not at their target goal BP. ${ }^{3}$ While office blood pressure monitoring (OBPM) is the usual care or gold standard for hypertension
Correspondence: Tonya L BreauxShropshire

Vascular Biology and Hypertension Program, Cardiovascular Disease, School of Medicine, University of Alabama at Birmingham, 933 19th Street South, Birmingham, Alabama 35233, USA. Email tshropshire@uab.edu 
diagnosis and treatment, home blood pressure monitoring (HBPM) improves BP control ${ }^{4}$ and medication adherence. ${ }^{5}$ A 24-hour ambulatory blood pressure monitoring (ABPM) is useful where there is uncertainty in diagnosis, resistant treatment, irregular variation or concerns about variability, and white coat or masked hypertension. It has been shown that HBPM correlates with ABPM, ${ }^{6-8}$ and cost and inconvenience are reasons why ABPM is not routinely recommended for the evaluation of patients with essential hypertension. ${ }^{9,10}$ HBPM is "easy to perform, reliable, reproducible", ${ }^{11-13}$ and has the potential to reduce treatment costs, office visits, and the number of medications. ${ }^{12,14,15}$ Furthermore, HBPM independently predicts cardiovascular morbidity and mortality. ${ }^{16,17}$

To date, it is unknown whether physicians can target HBPM for hypertension treatment. Few studies have examined the use of medication intensification guided by HBPM. ${ }^{18}$ However, the current clinical standard of OBPM is less likely related to target organ damage and may have less prospective value than HBPM. ${ }^{19,20}$ This review summarizes available data to answer the following question: "How does HBPM compare with ABPM as a measurement standard for determining BP control and patient outcomes?"

\section{Methods}

\section{Eligibility criteria}

Included studies contained both HBPM and ABPM as well as any of the following outcomes, BP control, myocardial infarction, diabetes mellitus, chronic kidney disease (CKD), stroke, or all-cause mortality. Study selection was limited to the adult population, $>18$ years of age. Exclusion criteria included: non-English language, BP monitor validation trials, untreated hypertension, or study size $<50$ participants. In addition, simple correlation studies between ABPM and HBPM were excluded. We were careful not to include duplicate data that were presented in different articles. Race was frequently left out of the demographics. Very few studies reported participant income and education level for results coding.

\section{Search strategy}

Literature searches were performed by a librarian in four databases during March-April 2014: PubMed, CINAHL (EBSCO), Scopus, and Cochrane Central (Wiley). The following databases (all years) were searched: PubMed, CINAHL (EBSCO), Scopus, and Cochrane Central Register of Controlled Trials (Wiley). Searches were constructed using subject headings when available keyword synonyms to include word variations and spellings. Searches took the following form, modified for each database: ((Blood Pressure Determination [MH:NoExp] OR Blood pressure OR BP [Text Word]) AND (determination [Text Word] OR monitor* OR measurement [Text Word])) AND (home OR HBP OR self [text word] OR Self Care [MH] OR telemedicine OR telemonitor* OR telemonitor OR HBPM [Text Word] OR SBPM [Text Word]) AND ((Blood pressure OR BP [Text Word] OR ABP) AND (determination [Text Word] OR monitor* OR measurement [Text Word])) AND (24hour OR 24-hour OR 24 hour OR “24h” OR “24hr” OR "24hr" OR ambulatory blood pressure monitoring [Text Word] OR blood pressure monitoring, ambulatory [MeSH Terms] OR ABPM [Text Word]) AND ("clinical trial" [Publication Type] OR “clinical trial” [All Fields] OR “comparative study" [Publication Type] OR "comparative study" [All Fields] OR "retrospective studies" [MeSH Terms] OR "retrospective studies" [All Fields] OR "case-control studies" [MeSH Terms] OR “case-control studies" [All Fields] OR “case-control studies" [All Fields] OR "follow-up studies” [MeSH Terms] OR “follow-up studies” [All Fields]).

\section{Selection of studies}

Two reviewers (TLBS and EJ) independently reviewed the titles and abstracts of the articles identified by the search strategy for potential relevance to the research question. A total of 2,714 titles and abstracts were identified of which 1,742 were screened after 972 duplicates were removed. Following this process, 137 potentially eligible full-text articles were reviewed, from which 2 reviewers identified 19 articles for inclusion in the paper. We synthesized these studies qualitatively (Figure 1).

\section{Data management and extraction}

Two reviewers (TLB-S and EJ) conducted the data extraction from papers selected to be included. The following data were extracted: participants, study design, study purpose, intervention, primary and secondary outcomes, and methodological quality. Differences in data extraction were resolved by consensus. Data extraction form was with explicit instructions that was created prior to the article review to ensure that both reviewers complete the form consistently. An evidence table was created to display the systematic overview of all studies lining up relevant data.

\section{Assessment of methodological quality}

The Jaded scale was used as a means of assessing the research methodology and scientific merit of randomized control trials. The Jaded scale is a validated scale that measures 


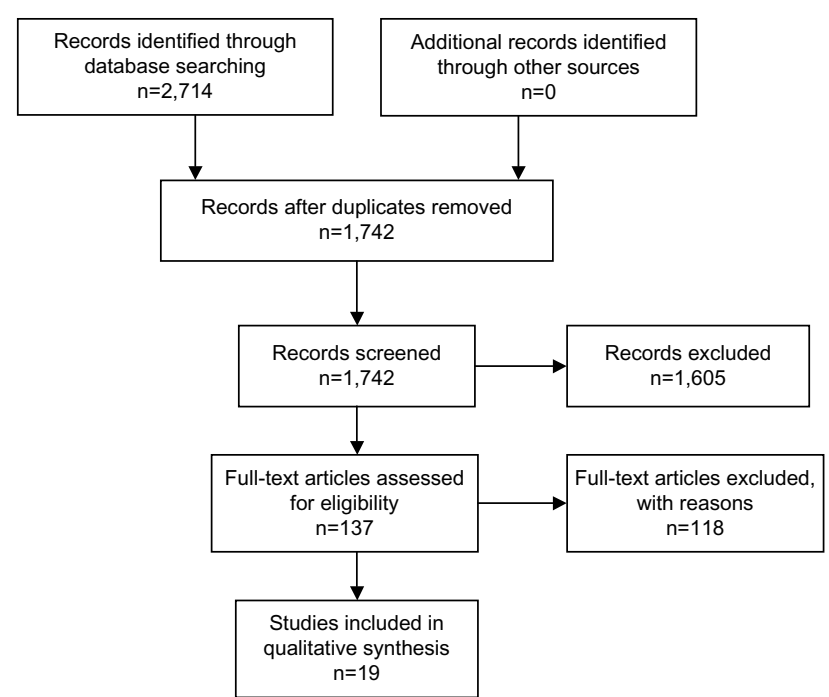

Figure I Flow diagram.

study quality by assigning a numeric score ranging from 1 to 5 based on methodological indicators such as randomization, double blinding, and descriptions of participant dropout data. ${ }^{21}$ Observational studies were assessed using Newcastle-Ottawa Scales.

\section{Data synthesis}

Relevant data were synthesized qualitatively to combine the results and to draw conclusions from the findings. Data limitations prevented subgroup analyses. Subgroup analyses were not performed due to a limited number of studies with identical or similar outcomes.

\section{Results \\ Study characteristics}

From the search, 19 studies were included in this systematic review. Studies were grouped into three main categories by study outcome: mortality, target organ damage, and BP control (Table 1). Five studies investigated associations between BP measurement type (eg, OBPM, HBPM, and ABPM) and mortality. These studies consisted of observational analyses in distinct populations, including patients with $\mathrm{CKD}$ or end-stage kidney disease in the United States, ${ }^{22,23}$ patients $\geq 60$ years of age from a single primary care practice in Belgium, ${ }^{24}$ and the general populations in Japan ${ }^{25}$ and Italy. ${ }^{26}$ Sample sizes ranged from 210 to 2,051 participants with median follow-up times between 2.4 and 12.3 years (Table 1 ).

Four studies compared target organ damage between the different BP measurement types. Target organ damage was measured as urine albumin-to-creatinine ratio, left ventricular hypertrophy by either electrocardiogram or echocardiogram, pulse wave velocity, or flow-mediated dilation of the brachial artery. Two studies were cross-sectional analyses with a single time point of data collection, ${ }^{27,28}$ and two were prospective designs with follow-up times of 6 and 12 months. ${ }^{18,29}$ Sample sizes ranged from 59 to 854 participants (Table 1).

The remaining ten studies contained all three types of BP measurement (OBPM, HBPM, and ABPM) and BP control data. Two were cross-sectional observational analyses, ${ }^{30,31}$ five were randomized controlled trials, ${ }^{32-36}$ and three were quasi-experimental studies without an active intervention ${ }^{37,38}$ or a control group..$^{39}$ The majority of study populations consisted of individuals with mild-to-moderate hypertension, either treated or untreated. Trials were short in length ranging from 4 weeks to 6 months. Antihypertensive medication formed the intervention for three of the five randomized controlled trials. Two trials randomized participants to have their BP medication adjusted according to HBPM vs OBPM ${ }^{33}$ or HBPM vs ABPM. ${ }^{36}$

\section{Study findings}

The major findings of each study are summarized in Table 1. Associations between BP measurement type (eg, OBPM, HBPM, and ABPM) and mortality differ by study population. In patients with CKD or end-stage kidney disease, ABPM is a superior predictor of mortality. ${ }^{22,23}$ For persons $\geq 60$ years of age, HBPM is as good or better than ABPM when predicting mortality in older patients. ${ }^{24}$ In the general population, additional BP information regardless of measurement type (OBPM, HBPM, and ABPM) contributes to cardiovascular risk. ${ }^{26}$ However, only BP assessed by HBPM and ABPM is associated with all-cause mortality. ${ }^{25}$

Data describing associations between BP measurement type and target organ damage are limited with only four studies meeting inclusion criteria. In general, arterial stiffness (measured by pulse wave velocity), albuminuria, and left ventricular mass were associated with changes in BP regardless of measurement type..$^{18,28}$

Regarding BP control, benefits emerge when including HBPM. In patients receiving hemodialysis, targeting antihypertensive treatment to home BPs as opposed to predialysis BPs results in better BP control, as assessed by ABPM. ${ }^{33}$ Fuchs et al showed that merely randomizing an individual to HBPM and not making any antihypertensive medication adjustments improves BP control. ${ }^{38}$ Using HBPM to titrate antihypertensive medication produces the same level of control as using ABPM. ${ }^{36}$

Targeting OBPM for control is limited by the low sensitivity of office BP to detect optimal BP control defined by 
Table I Studies included in the systematic review

\begin{tabular}{|c|c|c|c|c|c|c|}
\hline & Study population & $\begin{array}{l}\text { Study } \\
\text { type }\end{array}$ & $\begin{array}{l}\text { Study } \\
\text { location }\end{array}$ & $\begin{array}{l}\text { Study period } \\
\text { (year) }\end{array}$ & $\mathbf{n}$ & $\begin{array}{l}\text { Median } \\
\text { follow-up (year) }\end{array}$ \\
\hline \multicolumn{7}{|c|}{ Studies including mortality as an outcome } \\
\hline Agarwal $^{22}$ & Long-term dialysis & Obs & United States & $2003-2009$ & 326 & 2.4 \\
\hline Agarwal and & Veterans with CKD & Obs & United States & 2000-2002 & 210 & 3.4 \\
\hline \multicolumn{7}{|l|}{ Andersen ${ }^{23}$} \\
\hline Fagard et $\mathrm{al}^{24}$ & $\begin{array}{l}\text { Older patients ( } \geq 60 \text { years) } \\
\text { in a single primary care practice }\end{array}$ & Obs & Belgium & $1990-2003$ & 391 & 10.9 \\
\hline Imai et $\mathrm{al}^{25}$ & $\begin{array}{l}\text { General population } \\
\text { aged }>50 \text { years }\end{array}$ & Obs & Japan & $1987-1994$ & 893 & $4.5-5.2^{*}$ \\
\hline Mancia et $\mathrm{al}^{26}$ & $\begin{array}{l}\text { General population } \\
\text { aged } 25-74 \text { years }\end{array}$ & Obs & Italy & $1990-2004$ & 2,051 & $12.3 *$ \\
\hline \multicolumn{7}{|c|}{ Studies with target organ damage as an outcome } \\
\hline Coll-De-Tuero et $\mathrm{al}^{29}$ & Incident HTN & Obs & Spain & 2004-2007 & 479 & 1 \\
\hline Cuspidi et $\mathrm{al}^{27}$ & Treated HTN & QE & Italy & 2002 & 72 & 0 (single time point) \\
\hline Eguchi et al ${ }^{18}$ & $\begin{array}{l}\text { Uncontrolled HTN + DM2/ } \\
\text { prediabetes }\end{array}$ & QE & Japan & 2011 & 59 & 0.5 week \\
\hline Ishikawa et a|28 & $\begin{array}{l}\text { Adults with } \geq \text { I cardiovascular } \\
\text { risk factor }\end{array}$ & Obs & Japan & $2005-2010$ & 854 & 0 (cross-sectional) \\
\hline \multicolumn{7}{|c|}{ Studies assessing BP control } \\
\hline Bailey et $\mathrm{al}^{37}$ & Uncontrolled HTN & $\mathrm{QE}$ & Australia & 1998 & 60 & 8 weeks \\
\hline Beitelshees et a ${ }^{32}$ & Essential HTN & $\mathrm{RCT}$ & United States & 2010 & 363 & 12 weeks \\
\hline da Silva et $\mathrm{al}^{33}$ & Hemodialysis + HTN & $\mathrm{RCT}$ & Brazil & 2006-2007 & 65 & 0.5 week \\
\hline Felix-Redondo et al ${ }^{30}$ & Essential HTN & Obs & Spain & 2008 & 237 & 0 (cross-sectional) \\
\hline Fuchs et $\mathrm{a}^{38}$ & Treated, uncontrolled HTN & QE & Brazil & 2008-2009 & 121 & 8 weeks \\
\hline Mancia et $\mathrm{al}^{31}$ & Treated HTN, aged $25-74$ years & Obs & Italy & $1990-1993$ & 339 & 0 (cross-sectional) \\
\hline Mancia et $\mathrm{al}^{34}$ & Mild-to-moderate HTN & RCT & Italy, UK, NL & $|996-200|$ & 426 & 8 weeks \\
\hline Mengden et $\mathrm{al}^{35}$ & Mild-to-moderate HTN & RCT & SL & $199 \mid$ & 51 & 4 weeks \\
\hline Niiranen et $\mathrm{al}^{36}$ & Mild-to-moderate HTN & RCT & Finland & 1999-2003 & 98 & 0.5 week \\
\hline Scholze et $\mathrm{al}^{39}$ & Mild-to-moderate HTN & $\mathrm{QE}$ & Germany & $2009-2010$ & 53 & 12 weeks \\
\hline
\end{tabular}

Note: *Mean (median not reported).

Abbreviations: ABPM, ambulatory blood pressure monitoring; BP, blood pressure; CKD, chronic kidney disease; CV, cardiovascular; DBP, diastolic blood pressure; DM2, diabetes mellitus type 2; ECG, electrocardiogram; FMD, flow-mediated dilation; HBPM, home blood pressure monitoring; HTN, hypertension; LV, left ventricular; LVH, left ventricular hypertrophy; LVPI, left ventricular power index; MI, myocardial infarction; n, sample size; NL, the Netherlands; Obs, observational; PMV, pulse wave velocity; QE, quasi-experimental; RCT, randomized controlled trial; SBP, systolic blood pressure; UACR, urine albumin-to-creatinine ratio; UK, United Kingdom; SL, Switzerland.

either HBPM or ABPM (50\% and 53.4\%, respectively). ${ }^{30}$ Many studies agree that the correlation between HBPM and ABPM is stronger than that of OBPM with ABPM. ${ }^{29,32,34,35,39}$ However, in the general hypertensive population, HBPM can result in fewer prescribed medications with less BP control. $^{37}$

\section{Discussion}

The systematic selection of studies containing both HBPM and ABPM produced only 19 unique studies with a combined number of study participants near 7,100. Data were too limited to determine the benefit of using HBPM as a BP target when adjusting antihypertensive medications. This lack of data in the highly studied hypertensive population is a major finding in and of itself. However, clinically relevant conclusions can still be drawn from our review.

All of the studies that evaluated the relationship between OBPM, HBPM, and ABPM found HBPM to be correlated with $\mathrm{ABPM}$ and this correlation was stronger than that of OBPM and ABPM..$^{29,32,34-36}$ This agreement in combination with the 


\begin{tabular}{|c|c|}
\hline Outcome(s) & Major findings \\
\hline All-cause mortality & $\begin{array}{l}\text { Quartiles of SBP were strongly related to the hazard ratio for all-cause mortality with ABPM, less strongly with HBPM, } \\
\text { and not related with dialysis-unit BP }\end{array}$ \\
\hline $\begin{array}{l}\text { Combined total } \\
\text { mortality, MI, and stroke }\end{array}$ & $\begin{array}{l}\text { Only HTN defined by ABPM predicted cardiovascular outcomes, whereas definitions based on in-clinic BP or HBPM did } \\
\text { not predict CV outcomes }\end{array}$ \\
\hline Combined cardiovascular & SBP by HBPM and ABPM predicted major cardiovascular events while office SBP did not \\
\hline death, Ml, or stroke & Prognostic value of home $\mathrm{BP}$ was equal to (SBP) or better than (DBP) that of daytime BP by $\mathrm{ABPM}$ \\
\hline $\begin{array}{l}\text { All-cause mortality, } \\
\text { cardiovascular mortality }\end{array}$ & BP assessed by HBPM and ABPM was associated with mortality, while casual BP screening was not \\
\hline $\begin{array}{l}\text { Cardiovascular and non- } \\
\text { cardiovascular mortality }\end{array}$ & $\begin{array}{l}\text { Elevated BP by office measurement, HBPM, or ABPM each contribute to the risk of cardiovascular mortality when } \\
\text { added to other BP elevations }\end{array}$ \\
\hline UACR, LVH by ECG & $\begin{array}{l}\text { One year changes in SBP were closer between HBPM and daytime ABPM than clinic measurement. No changes in } \\
\text { UACR or LVH by ECG were seen }\end{array}$ \\
\hline LVH by echocardiogram & $\begin{array}{l}\text { LVH was more prevalent among participants with uncontrolled office BP compared with controlled office BP, despite } \\
\text { similar control by ABPM and HBPM }\end{array}$ \\
\hline FMD, PWV, UACR & $\begin{array}{l}\text { Changes in PWV and UACR were associated with changes in BP regardless of measurement type. Changes in FMD } \\
\text { were only associated with changes in BP by HBPM }\end{array}$ \\
\hline UACR, LVPI mass index & $\begin{array}{l}\text { SBP measured by ABPM, HBPM, and clinic was associated with natural log-transformed UACR and LV mass index. } \\
\text { Correlation with UACR was strongest for SBP by HBPM }\end{array}$ \\
\hline BP control & Participants randomized to HBPM had higher SBP by ABPM and fewer BP medications when compared with usual care \\
\hline BP control & $\begin{array}{l}\text { Office } \mathrm{BP} \text { overestimated SBP response to therapy by an average of } 4.6 \mathrm{mmHg} \text { when compared with home } \mathrm{BP} \\
\text { Correlation with } \mathrm{ABPM} \text { was higher for home compared with office } \mathrm{BP}(r=0.58 \text { and } 0.47 \text {, respectively) }\end{array}$ \\
\hline $\begin{array}{l}\text { BP control, } \\
\text { LV mass index }\end{array}$ & $\begin{array}{l}\text { Adjusting antihypertensive therapy by HBPM as opposed to predialysis BP measurement resulted in a greater reduction } \\
\text { in SBP by ABPM }(135 \pm 12 \text { vs } 147 \pm 15 \mathrm{mmHg}, P<0.05) \\
\text { No difference was seen in LV mass index }\end{array}$ \\
\hline BP control & $\begin{array}{l}\text { Conventional office BP had a low sensitivity to detect optimal BP control by either HBPM or ABPM ( } 50 \% \text { and } 53.4 \% \text {, } \\
\text { respectively) }\end{array}$ \\
\hline BP control & $\begin{array}{l}\text { Randomizing participants to HBPM without medication titration improves BP control by ABPM ( } 32.4 \% \text { vs } 16.2 \% \text { control } \\
\text { rates, respectively; } P=0.03)\end{array}$ \\
\hline BP control & BP control was similar when assessed by clinic, HBPM, or ABPM \\
\hline BP control & $\mathrm{BP}$ reductions were similar for HBPM and ABPM \\
\hline BP control & $\begin{array}{l}\text { Change in mean SBP and DBP as measured by HBPM and ABPM were correlated }(r=0.4, P<0.05 \text { for } \triangle \mathrm{SBP} ; r=0.6 \text {, } \\
P<0.0005 \text { for } \triangle \mathrm{DBP})\end{array}$ \\
\hline BP control & No difference was seen in BP control when randomized to antihypertension medication adjustment by HBPM or ABPM \\
\hline BP control & $\begin{array}{l}\text { BP reductions were poorly correlated between office monitoring and ABPM ( } r=0.05 \text { for } \triangle \mathrm{SBP}) \text {. Correlation of } \triangle \mathrm{SBP} \\
\text { between HBPM and ABPM was } 0.14\end{array}$ \\
\hline
\end{tabular}

low sensitivity of office BP to detect optimal BP control by $\mathrm{ABPM}^{30}$ and the added association of HBPM with cardiovascular mortality $^{26}$ all support the use of HBPM when treating hypertension. It is not surprising that routine use of HBPM has been recommend for almost a decade. ${ }^{40}$ Currently, the American Heart Association, the American Society of Hypertension, and the Preventive Cardiovascular Nurses Association suggest that HBPM be incorporated into usual care. ${ }^{41}$

By comparison, HBPM has some advantages over ABPM. The availability of affordable BP monitoring devices has allowed individuals to measure and record BPs repeatedly throughout their course of treatment. In contrast, ABPM is not directly available to patients, and its high cost presents a barrier to initial and repeated testing. By requiring the individual to wear the cuff and monitor continuously, ABPM does interfere with daily activities and sleep. Although, any advantage in convenience or comfort with HBPM is weighed against the superior standardization of BP measurement and the acquisition of sleep-time BP data by 24-hour ABPM. 
It is important to note that large randomized trials investigating hypertension treatment have targeted BP measured during study visits, similar to OBPM, when evaluating medication efficacy and participant outcomes. For this reason, HBPM should not supplant OBPM. While the addition of HBPM will help physicians to identify patients with maskeduncontrolled hypertension (ie, individuals controlled in the office yet uncontrolled at home), in patients with low home BPs, HBPM data can adversely affect treatment decisions. The study by Bailey et al offers a reminder to physicians that care must be taken when incorporating HBPM data into treatment strategies. Physician behavior was influenced by HBPM readings and resulted in fewer prescribed medications; systolic BP by 24-hour ABPM was $137 \pm 3 \mathrm{mmHg}$ for the group randomized to HBPM compared with $130 \pm 3$ $\mathrm{mmHg}$ in the usual care group. ${ }^{37}$

However, HBPM can improve BP control through its indirect effects on patients. HBPM encourages patient-centered care. Self-monitoring of BP reminds patients of the importance of medication adherence and healthy lifestyle factors. The study by Fuchs et al supports these indirect effects of self-monitoring. Participating in HBPM alone improved BP control. ${ }^{38}$

\section{Limitations}

In the review process, we identified numerous studies with both HBPM and ABPM data that were designed as validation studies for BP monitoring devices. While these studies do contain information regarding BP control, they did not align with our interpretation of the outcome of BP control. Variability existed in the timing of HBPM both in the length of monitoring time (2-14 days) and in the frequency of measurement (two to six times per day). On the other hand, ABPM was more consistent with measurements every 15-20 minutes while awake and 15-30 minutes while asleep for a total of 24-44 hours.

An important distinction between HBPM and ABPM is the inclusion of nocturnal measurements with ABPM. We did not pursue outcome associations with isolated nocturnal hypertension. Furthermore, this study examined the effect of BP measurement type on BP control and clinical outcomes, yet did not attempt to answer the question of what is the goal BP.

\section{Conclusion}

Our findings support the guideline recommendations to include HBPM in the management of hypertension. The benefits of identifying masked-uncontrolled hypertension and increasing patient participation in his/her care outweigh the risk of undertreating patients with white coat phenomena.

\section{Disclosure}

The authors report no conflicts of interest in this work.

\section{References}

1. Chobanian AV, Bakris GL, Black HR, et al. The Seventh Report of the Joint National Committee on Prevention, Detection, Evaluation, and Treatment of High Blood Pressure: the JNC 7 report. JAMA. 2003;289(19):2560-2572.

2. James PA, Oparil S, Carter BL, et al. 2014 evidence-based guideline for the management of high blood pressure in adults: report from the panel members appointed to the Eighth Joint National Committee (JNC 8). JAMA. 2014;311(5):507-520.

3. Centers for Disease Control and Prevention (CDC). Vital signs: awareness and treatment of uncontrolled hypertension among adults - United States, 2003-2010. MMWR Morb Mortal Wkly Rep. 2012;61: 703-709.

4. Cappuccio FP, Kerry SM, Forbes L, Donald A. Blood pressure control by home monitoring: meta-analysis of randomised trials. $\mathrm{Br}$ Med J. 2004;329(7458):145-148.

5. Ogedegbe GO, Boutin-Foster C, Wells MT, et al. A randomized controlled trial of positive-affect intervention and medication adherence in hypertensive African Americans. Arch Intern Med. 2012;172(4): 322-326.

6. Stergiou GS, Baibas NM, Gantzarou AP, et al. Reproducibility of home, ambulatory, and clinic blood pressure: implications for the design of trials for the assessment of antihypertensive drug efficacy. Am J Hypertens. 2002;15(2 Pt1):101-104.

7. Mule G, Caimi G, Cottone S, et al. Value of home blood pressures as predictor of target organ damage in mild arterial hypertension. J Cardiovasc Risk. 2002;9(2):123-129.

8. Tsunoda S, Kawano Y, Horio T, Okuda N, Takishita S. Relationship between home blood pressure and longitudinal changes in target organ damage in treated hypertensive patients. Hypertens Res. 2002;25(2): 167-173.

9. Mancia G, Bombelli M, Brambilla G, et al. Long-term prognostic value of white coat hypertension: an insight from diagnostic use of both ambulatory and home blood pressure measurements. Hypertension. 2013;62(1):168-174.

10. Weber MA, Schiffrin EL, White WB, et al. Clinical practice guidelines for the management of hypertension in the community a statement by the American Society of Hypertension and the International Society of Hypertension. J Hypertens. 2014;32(1):3-15.

11. Pickering TG, Miller NH, Ogedegbe G, Krakoff LR, Artinian NT, Goff D. Call to action on use and reimbursement for home blood pressure monitoring: a joint scientific statement from the American Heart Association, American Society of Hypertension, and Preventive Cardiovascular Nurses Association. J Cardiovasc Nurs. 2008;23(4): 299-323.

12. Appel LJ, Stason WB. Ambulatory blood pressure monitoring and blood pressure self-measurement in the diagnosis and management of hypertension. Ann Intern Med. 1993;118(11):867-882.

13. Mejia A, Julius S. Practical utility of blood pressure readings obtained by self-determination. J Hypertens Suppl. 1989;7(3):S53-S57.

14. Soghikian K, Casper SM, Fireman BH, et al. Home blood pressure monitoring. Effect on use of medical services and medical care costs. Med Care. 1992;30(9):855-865.

15. Staessen JA, Byttebier G, Buntinx F, Celis H, O’Brien ET, Fagard R. Antihypertensive treatment based on conventional or ambulatory blood pressure measurement. A randomized controlled trial. Ambulatory Blood Pressure Monitoring and Treatment of Hypertension Investigators. JAMA. 1997;278(13):1065-1072. 
16. Jula A, Puukka P, Karanko H. Multiple clinic and home blood pressure measurements versus ambulatory blood pressure monitoring. Hypertension. 1999;34(2):261-266.

17. Shimbo D, Pickering TG, Spruill TM, Abraham D, Schwartz JE, Gerin W. Relative utility of home, ambulatory, and office blood pressures in the prediction of end-organ damage. Am J Hypertens. 2007;20(5): 476-482.

18. Eguchi K, Hoshide S, Ishikawa S, Shimada K, Kario K. Aggressive blood pressure-lowering therapy guided by home blood pressure monitoring improves target organ damage in hypertensive patients with type 2 diabetes/prediabetes. J Clin Hypertens (Greenwich). 2012;14(7):422-428.

19. Gaborieau V, Delarche N, Gosse P. Ambulatory blood pressure monitoring versus self-measurement of blood pressure at home: correlation with target organ damage. J Hypertens. 2008;26(10):1919-1927.

20. Stergiou GS, Argyraki KK, Moyssakis I, et al. Home blood pressure is as reliable as ambulatory blood pressure in predicting target-organ damage in hypertension. Am J Hypertens. 2007;20(6):616-621.

21. Jadad AR, Moore RA, Carroll D, et al. Assessing the quality of reports of randomized clinical trials: is blinding necessary? Control Clin Trials. 1996;17(1):1-12.

22. Agarwal R. Blood pressure and mortality among hemodialysis patients. Hypertension. 2010;55(3):762-768.

23. Agarwal R, Andersen MJ. Blood pressure recordings within and outside the clinic and cardiovascular events in chronic kidney disease. Am J Nephrol. 2006;26(5):503-510.

24. Fagard RH, Van Den Broeke C, De Cort P. Prognostic significance of blood pressure measured in the office, at home and during ambulatory monitoring in older patients in general practice. J Hum Hypertens. 2005;19(10):801-807.

25. Imai Y, Ohkubo T, Sakuma M, et al. Predictive power of screening blood pressure, ambulatory blood pressure and blood pressure measured at home for overall and cardiovascular mortality: a prospective observation in a cohort from Ohasama, northern Japan. Blood Press Monit. 1996;1(3):251-254.

26. Mancia G, Facchetti R, Bombelli M, Grassi G, Sega R. Long-term risk of mortality associated with selective and combined elevation in office, home, and ambulatory blood pressure. Hypertension. 2006;47(5): 846-853.

27. Cuspidi C, Michev I, Meani S, et al. Left ventricular hypertrophy in treated hypertensive patients with good blood pressure control outside the clinic, but poor clinic blood pressure control. J Hypertens. 2003; 21(8):1575-1581.

28. Ishikawa J, Hoshide S, Eguchi K, Ishikawa S, Shimada K, Kario K. Night time home blood pressure and the risk of hypertensive target organ damage. Hypertension. 2012;60(4):921-928.

29. Coll-De-Tuero G, Saez M, Rodriguez-Poncelas A, et al. Why is cardiovascular risk stratification important in hypertensive patients? Blood Pressure. 2012;21(3):182-190.
30. Felix-Redondo FJ, Fernandez-Berges D, Espinosa-Garcia J, et al. Level of blood pressure control in a hypertensive population when measurements are performed outside the clinical setting. Cardiol J. 2009;16(1): 57-67.

31. Mancia G, Bombelli M, Lanzarotti A, et al. Systolic vs diastolic blood pressure control in the hypertensive patients of the PAMELA population. Arch Intern Med. 2002;162(5):582-586.

32. Beitelshees AL, Gong Y, Bailey KR, et al. Comparison of office, ambulatory, and home blood pressure antihypertensive response to atenolol and hydrochlorthiazide. J Clin Hypertens (Greenwich). 2010;12(1):14-21.

33. da Silva GV, de Barros S, Abensur H, Ortega KC, Mion D Jr. Home blood pressure monitoring in blood pressure control among haemodialysis patients: an open randomized clinical trial. Nephrol Dial Transplant. 2009;24(12):3805-3811.

34. Mancia G, Korlipara K, van Rossum P, Villa G, Silvert B. An ambulatory blood pressure monitoring study of the comparative antihypertensive efficacy of two angiotensin II receptor antagonists, irbesartan and valsartan. Blood Press Monit. 2002;7(2):135-142.

35. Mengden T, Binswanger B, Weisser B, Vetter W. An evaluation of selfmeasured blood pressure in a study with a calcium-channel antagonist versus a beta-blocker. Am J Hypertens. 1992;5(3):154-160.

36. Niiranen TJ, Kantola IM, Vesalainen R, Johansson J, Ruuska MJ. A comparison of home measurement and ambulatory monitoring of blood pressure in the adjustment of antihypertensive treatment. Am J Hypertens. 2006;19(5):468-474.

37. Bailey B, Carney SL, Gillies AA, Smith AJ. Antihypertensive drug treatment: a comparison of usual care with self blood pressure measurement. J Hum Hypertens. 1999;13(2):147-150.

38. Fuchs SC, Ferreira-da-Silva AL, Moreira LB, et al. Efficacy of isolated home blood pressure monitoring for blood pressure control: randomized controlled trial with ambulatory blood pressure monitoring MONITOR study. J Hypertens. 2012;30(1):75-80.

39. Scholze J, Bramlage P, Trenkwalder P, Kreutz R. Efficacy and safety of a fixed-dose combination of lercanidipine and enalapril in daily practice. A comparison of office, self-measured and ambulatory blood pressure. Expert Opin Pharmacother. 2011;12(18):2771-2779.

40. Pickering TG, Hall JE, Appel LJ, et al. Recommendations for blood pressure measurement in humans and experimental animals: part 1 blood pressure measurement in humans: a statement for professionals from the Subcommittee of Professional and Public Education of the American Heart Association Council on High Blood Pressure Research. Circulation. 2005;111(5):697-716.

41. Pickering TG, Miller NH, Ogedegbe G, Krakoff LR, Artinian NT, Goff D. Call to action on use and reimbursement for home blood pressure monitoring: a joint scientific statement from the American Heart Association, American Society Of Hypertension, and Preventive Cardiovascular Nurses Association. Hypertension. 2008;52(1): $10-29$

Integrated Blood Pressure Control

\section{Publish your work in this journal}

Integrated Blood Pressure Control is an international, peer-reviewed open-access journal focusing on the integrated approach to managing hypertension and risk reduction. Treating the patient and comorbidities together with diet and lifestyle modification and optimizing healthcare resources through a multidisciplinary team approach constitute key

\section{Dovepress}

features of the journal. This journal is indexed on American Chemical Society's Chemical Abstracts Service (CAS). The manuscript management system is completely online and includes a very quick and fair peerreview system, which is all easy to use. Visit http://www.dovepress.com/ testimonials.php to read real quotes from published authors. 